See Article page 1.

\section{Commentary: Subclavian artery cannulation in aortic arch surgery_-Mind your mind!}

\author{
Mohamad Bashir, MD, PhD, MRCS, ${ }^{\mathrm{a}}$ and \\ Tomas A. Salerno, MD $^{\mathrm{b}}$
}

Total arch replacement, with or without the use of specific device technology, has been through multiple stages of consistency, simplicity, and innovation to ensure it is reproducible. This approach, however, is fraught with technical challenges, especially regarding the position and anatomy of the subclavian arteries. This is imperative, as it allows the surgeon to strategically orient the surgical decision-making before initiating repair of the arch, albeit in elective and emergent settings. Cannulation of the right subclavian artery, to optimize and attain safe cerebral protection during arch surgery, has been described previously. ${ }^{1-3}$ This technique not only allows continuous antegrade perfusion but is paired with selective cerebral antegrade perfusion during circulatory arrest. This avoids organ malperfusion and the potential for neurologic damage. Yet, this entity remains a station for debate among different groups, and the discussion has moved not to the delivery method, size, and orientation but also the approach for cerebral perfusion during circulatory arrest. This brings us to the article by Regesta and colleagues, ${ }^{4}$ who report their experience and results of single sternotomy access for right subclavian artery cannulation. This is performed without an infraclavicular incision during surgery of the thoracic aorta.

\footnotetext{
From the ${ }^{\text {a}}$ Health Education \& Improvement Wales, Vascular \& Endovascular Surgery, Wales, United Kingdom; and ${ }^{\mathrm{b}}$ University of Miami/Jackson Memorial Hospital, Miami, Fla.

Disclosures: The authors reported no conflicts of interest.

The Journal policy requires editors and reviewers to disclose conflicts of interest and to decline handling or reviewing manuscripts for which they may have a conflict of interest. The editors and reviewers of this article have no conflicts of interest.

Received for publication April 24, 2021; revisions received May 15, 2021; accepted for publication May 21, 2021; available ahead of print June 15, 2021

Address for reprints: Tomas A. Salerno, MD, University of Miami/Jackson Memorial Hospital, P.O. Box 016960 (r-114), 1611 N.W. 12th Ave, ET 3072, Miami, FL 33136 (E-mail: tsalerno@med.miami.edu).

JTCVS Techniques 2021;8:9-10

2666-2507

Copyright (c) 2021 The Author(s). Published by Elsevier Inc. on behalf of The American Association for Thoracic Surgery. This is an open access article under the CC BY-NC-ND license (http://creativecommons.org/licenses/by-nc-nd/4.0/).

https://doi.org/10.1016/j.xjtc.2021.05.025
}

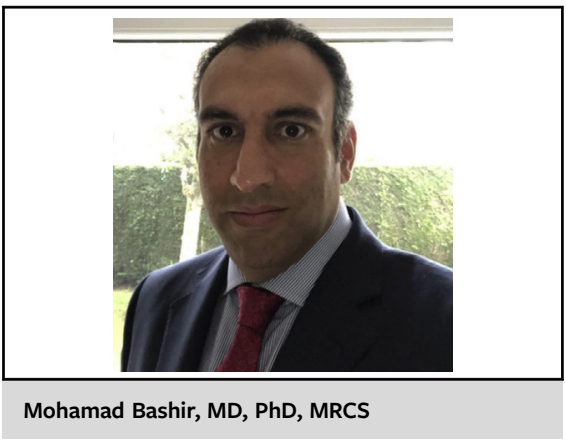

CENTRAL MESSAGE

Right subclavian artery cannulation to deliver brain protection during arch surgery is imperative. Deviating from this pivot to shorten the operating time is elusive and has no clinical ground.

The authors are to be commended for providing their current experience and their report on percutaneous right subclavian cannulation, or perfusion via a side-arm graft using a median sternotomy. ${ }^{5}$ They use this approach when the innominate artery is not suitable for arterial cannulation. The right subclavian artery, uncommonly affected by the acute dissection process, is cannulated either directly, or by sewing an end-to-side 8-mm polyester graft to the artery. This allows systemic flow with antegrade perfusion without the need for another surgical incision, other than sternotomy. Their reported experience highlights the advantages of this approach, honing down on the disadvantages of alternative surgical approaches, which are well described in the literature. The armamentarium for surgical approach to of the right subclavian artery in aortic arch repair has evolved with time, vast experience from stronghold, and pioneers in this field. It would have been of interest for the authors to report their approach for redo-arch surgery, which constitutes a major portion of the workload of surgeons in busy aortic centers. Aortic dissection repair is an aggressive, yet strategic, surgery with multiple layered assessments, including the need for reoperations for patients with previous arch surgery in some stage of their lives. The authors of this manuscript provide further insight into the different approaches for cerebral perfusion during circulatory arrest. 


\section{References}

1. Cavozza C, Campanella A, Pellegrino P, Regesta T, Gherli R, Audo A. Right subclavian artery cannulation for aortic dissection surgery, without infraclavicular incision. Multimed Man Cardiothorac Surg. 2020;2020:10.1510/mmcts.2020. 043. Published 2020 Aug 18.

2. Pawlaczyk R, Siondalski P, Anisimowicz L, Jagielak D, Jarmoszewicz K, Zelechowski P, et al. Kaniulacja prawej tetnicy podobojczykowej w chirurgicznym leczeniu ostrego rozwarstwienia aorty typu A [Right subclavian artery cannulation in surgery of acute type A aortic dissection]. Kardiol Pol. 2004;60(Suppl 1):93-6 [in Polish].
3. Reuthebuch O, Schurr U, Hellermann J, Prêtre R, Künzli A, Lachat M, et al. Advantages of subclavian artery perfusion for repair of acute type A dissection. Eur J Cardiothorac Surg. 2004;26:592-8.

4. Regesta T, Cavozza C, Campanella A, Pellegrino P, Gherli R, Maj G, et al. Direct proximal right subclavian artery cannulation during surgery of the thoracic aorta. J Thorac Cardiovasc Surg Tech. 2021;8:1-6.

5. Cavozza C, Campanella A, Pasquale P, Audo A. Percutaneous or side-arm graft right subclavian artery cannulation via median sternotomy. Aorta (Stamford). 2019;7:150-3. 